\title{
Minimally invasive treatment of benign complete stenosis of colorectal anastomosis
}

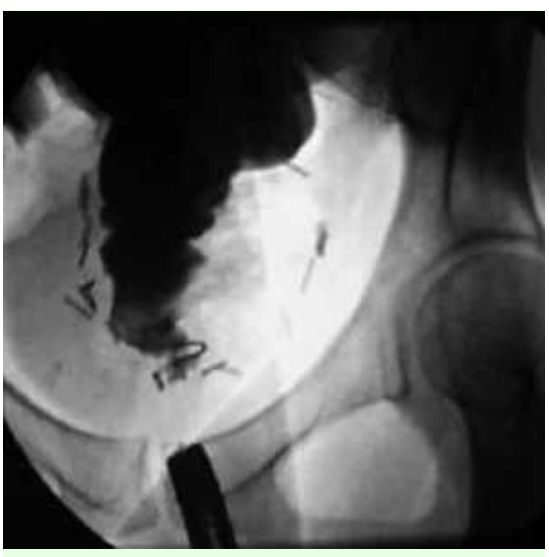

Fig. 1 Barium enema performed through the ileostomy.

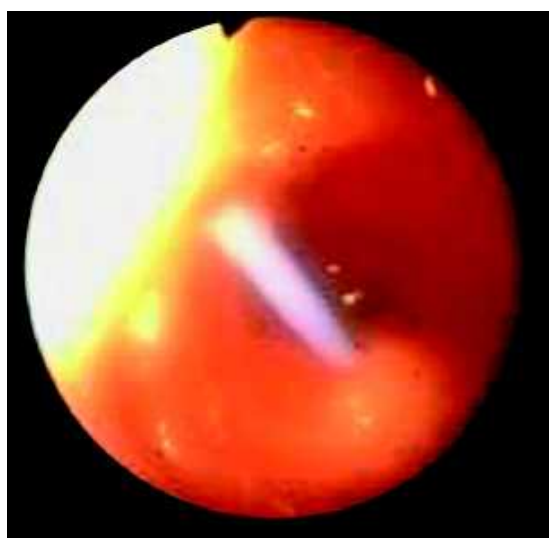

Fig. 2 Needle puncture under endoscopic vision.

The most frequent complications of colorectal surgery are leaks and stenosis, which occur with a frequency of $0.3 \%$ $30 \%[1,2]$. Strictures are commonly treated with conservative treatments such as balloon dilatation, endoscopic incision, and placement of self-expanding metal stent (SEMS) [3-5]. Two patients with complete colorectal anastomotic closure were successfully treated with an endoscopic-radiologic rendezvous procedure.

A 27-year-old woman who had undergone low anterior resection due to cancer of the rectum, and a 69-year-old man who had undergone left colonic resection because of acute diverticulitis were referred to our department. Both patients had a loop ileostomy. Endoscopic and radiologic follow-up before recanalization showed complete anastomotic stric-

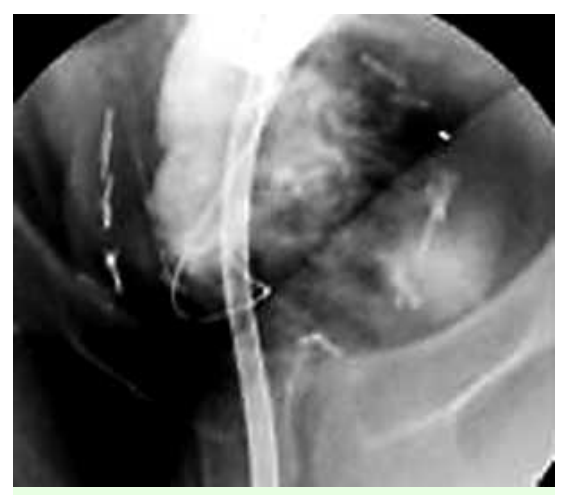

Fig. 3 Drainage catheter placed through the neo-anastomosis.

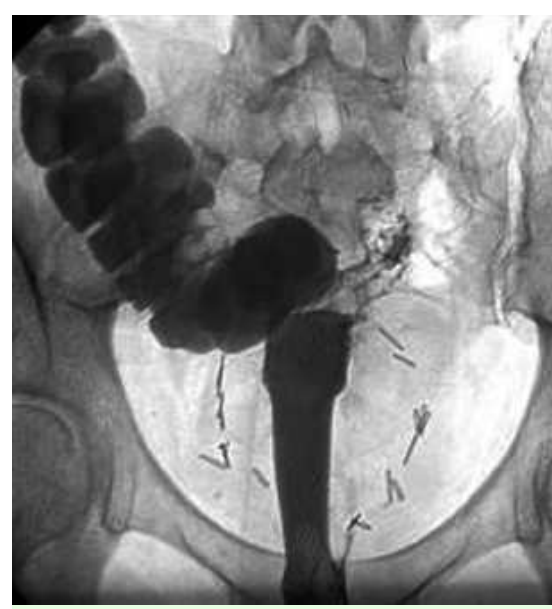

Fig. 4 Fully covered and removable self-expanding metal stent in place.

ture ( $\odot$ Fig. 1 ) at $8 \mathrm{~cm}$ and $16 \mathrm{~cm}$ from the anal verge, respectively. In both patients malignancy was excluded by means of multiple biopsies. Both patients were treated as follows. An incision of the fibrotic stenosis of the anastomosis was made through the rectum using a needle normally used for transjugular intrahepatic portosystemic shunt (TIPS). Direct vision of the puncture place was assured by an anterograde colonoscopy from the ileostomy ( $\bullet$ Fig. 2 ). A guide wire was passed through and a drainage catheter was placed. The drainage catheter was kept in place for 3 days ( $\$$ Fig. 3 ). Following two balloon dilatations, a fully covered and removable stent was placed (৫ Fig. 4). After 60 days, the stent was re-

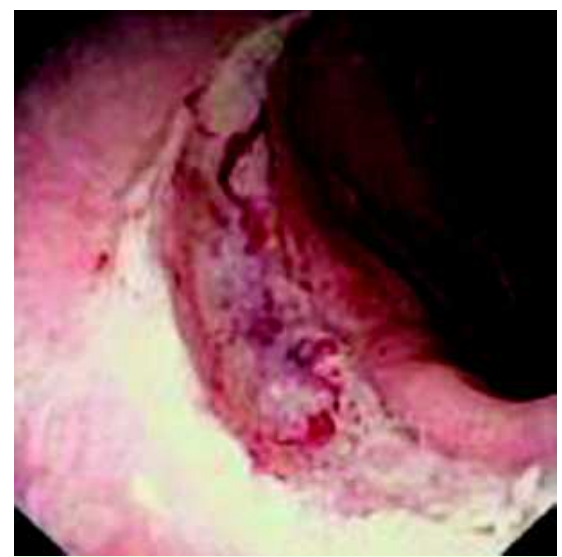

Fig. 5 Endoscopic check after removal of the self-expanding metal stent.

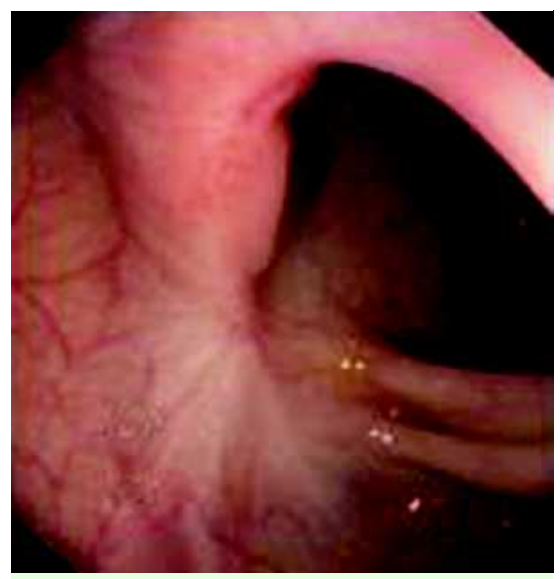

Fig. 6 Endoscopic check after 24 months.

moved ( $\bullet$ Fig. 5). In one patient the stent gave mild tenesmus, which was alleviated by analgesic drugs.

In both patients the neo-anastomosis ( Fig. 6) was still wide open and functioning well after 24 months. Even in such difficult cases, in which the use of surgery seemed inevitable and furthermore not free of risks, the cooperation between endoscopist and radiologist made conservative treatment possible. The placement of removable SEMS in order to maintain an adequate lumen and to eliminate any possible leak was demonstrated to be a safe and efficient technique.

Endoscopy_UCTN_Code_TTT_1AQ_2AF 
G. Donatelli ${ }^{1}$, V. Ceci ${ }^{1}$, F. Cereatti ${ }^{1}$,

A. Bruni ${ }^{2}$, F. M. Salvatori ${ }^{2}$, S. Minervini ${ }^{1}$,

F. Fiocca ${ }^{1}$

1 Department of General Surgery "Paride Stefanini", Rome, Italy

2 Department of Radiological Sciences, University of Rome “La Sapienza”, Rome, Italy

\section{References}

1 Platell C, Barwood N, Dorfmann G, Makin G. The incidence of anastomotic leaks in patients undergoing colorectal surgery. Colorectal Dis 2007; 9: 71 - 79

2 McKee R, Pricolo VE. Stapled revision of complete colorectal anastomotic obstruction. Am J Surg 2008; 195: 526-527

3 Forshaw MJ, Maphosa G, Sankararajah D et al. Endoscopic alternatives in managing anastomotic strictures of the colon and the rectum. Tech Coloproctol 2006; 10: 21-27

4 Rees JRE, Carney L, Gill TS, Dixon AR. Management of recurrent anastomotic stricture and iatrogenic stenosis by circular stapler Dis Colon Rectum 2004; 47: 944-947

5 Forshaw MJ, Sankararajah D, Stewart M, Parker MC. Use of self-expanding metallic stents for benign colorectal disease. Colorectal Dis 2006; 8: 102 - 111
Bibliography

DOI $10.1055 / \mathrm{s}-2008-1077660$

Endoscopy 2008; 40: E263-E264

(c) Georg Thieme Verlag KG Stuttgart · New York . ISSN 0013-726X

Corresponding author

\section{F. Fiocca, MD}

Department of General Surgery "Paride Stefanini" Viale del Policlinico 155

00161, Rome

Italy

Fax: +39-06-4940532

fausto.fiocca@uniroma1.it 